\title{
Characteristics of precipitable water over Peninsular Malaysia from satellite and in situ data
}

\author{
Ezekiel Kaura Makama ${ }^{1,2}$ and Hwee San Lim ${ }^{1, *}$ \\ ${ }^{1}$ School of Physics, Universiti Sains Malaysia, Malaysia \\ ${ }^{2}$ Department of Physics, University of Jos, Nigeria
}

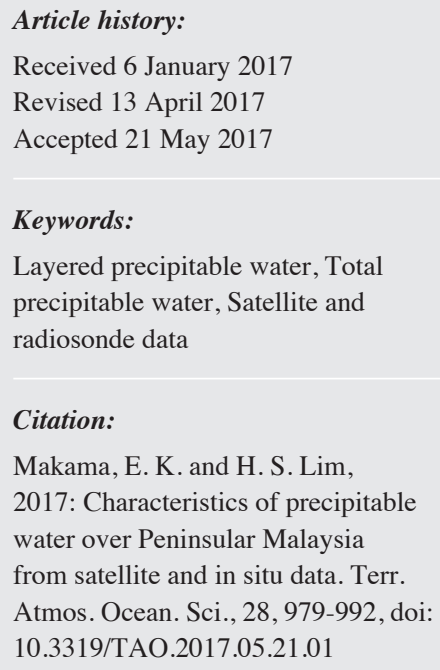

Makama, E. K. and H. S. Lim, 2017: Characteristics of precipitable water over Peninsular Malaysia from satellite and in situ data. Terr. Atmos. Ocean. Sci., 28, 979-992, doi: 10.3319/TAO.2017.05.21.01

\begin{abstract}
Variations as well as distribution patterns of total precipitable water vapour (WST) and layered precipitable water vapour (W) over Peninsular Malaysia using data retrieved and archived by the Satellite Application Facilities on Climate Monitoring (CM SAF), Deutscher Wetterdienst, Germany, for the period 2001 - 2011 are analysed using simple regression method. The lower and middle layers of $\mathrm{W}$ are observed to exhibit bimodal annual oscillations, which are in phase with WST at all the climatic regions, with a pair of minima and maxima in each case. The primary and secondary minima occur in February and August, while their maxima counterparts are noticed around November and May/June respectively. These oscillations are synchronous to the movement of the prevailing monsoons. The satellite and radiosonde products are compared at the seasonal scale and the results show good agreement, with correlation coefficients between $0.60-0.98$ and mean bias range of $-0.60-0.59 \mathrm{~kg} \mathrm{~m}^{-2}$ throughout the study area. Also at the seasonal scale WST and W exhibit significant agreement at all the stations for which radiosonde records were available. The difference between $\mathrm{W}$, from the two sources of measurements are relatively uniform, irrespective of the satellite value, at all the layers and to a large extend, throughout the period of the year. While the satellite precipitable water is greater than its radiosonde counterpart at the middle and upper layers, the reverse is, however, the case for the lower layer in all the climatic regions. These differences are more as a result of instrumentation than the variability of the atmosphere.
\end{abstract}

\section{INTRODUCTION}

Water vapor, which has high spatial and temporal variability, with values ranging from about $50 \mathrm{~mm}$ near the equator to less than one-tenth as much at the poles (Mockler 1995), is not only the most abundant, but also the most influential of all the major greenhouse gases in the atmosphere. It has an average residence time of about 8 days, with the tropical convergence zones condoning it for about 12 days while the residency at subtropical high regions are much shorter (Trenberth 1998).

The role played by the vapour phase of water in the hydrological cycle and its effects on the weather and climate systems (e.g., Follette-Cook et al. 2009) cannot be ignored. For instance, Jacob (2001) describes water vapour as a prin-

\footnotetext{
* Corresponding author

E-mail:hslim@usm.my
}

cipal element in the thermodynamics of the atmosphere that strongly modulates the propagation of solar and terrestrial radiation, leading to crucial impact on the Earth's radiation budget. Being a major greenhouse gas, water vapour is usually considered to play an amplifying role in global warming through a strongly positive climate feedback loop (Held and Soden 2000). The heat-amplifying effect of this humidity variable is potent in doubling the climate warming, caused by increased levels of carbon dioxide in the atmosphere. Knowledge of the distribution and temporal variation of atmospheric water vapor is also important in forecasting regional weather and for the understanding of the global climate system.

As a result of the foregoing, there is increasing interest in the measurement of atmospheric water vapour both at the surface and in its total abundance in a vertical column through the atmosphere. The columnar variation of water 
vapour, which is usually referred to as integrated or precipitable water vapour (PWV) is the main focus of this paper. PWV, usually measured in $\mathrm{mm}\left(\mathrm{kg} \mathrm{m}^{-2}\right)$, can be defined as the depth (or thickness) of liquid water that collects, if all the vapour in the zenith direction were condensed, at the surface of a unit area (Gruber and Watkins 1982).

The variability in space and time of PWV, as earlier mentioned, including its radiative features, poses a great challenge in its sampling and measurement. For instance, the variation of the horizontal mixing ratio is one order of magnitude at the surface between the tropics and the poles and its vertical component spans over four orders of magnitude from the surface to the lower stratosphere (Schulz and Selbach 2004). This explains why there are several different techniques employed by scientists to quantify the parameter. The techniques are either in situ (ground based, balloon or airborne), passive and active remote sensing such as LIDAR (Gerding et al. 2004), LASER systems (Eng et al. 1973) or satellite remote sensing (Mockler 1995; Chaboureau et al. 1998).

Radiosonde networks, considered to be the primary (or standard) in situ observing system for monitoring PWV, provide meteorological parameters such as pressure, temperature, relative humidity and occasionally, wind information. They are usually expected to estimate PWV with an uncertainty of a few kilograms per square metre, which is considered to be the accuracy standard of PWV for Meteorologists (Adeyemi and Joerg 2012). Apart from the high operational cost of radiosonde systems, they are spatially limited continentally and almost absent over the oceans. Although space borne observation platforms may be lacking in spatial resolution, they provide global coverage, thereby circumventing the paucity of ground measurements. Based on these, the satellite appears to be the most authentic method left for the global monitoring of PWV, hence the need to calibrate it with standard in situ data. However, because of high variability of PWV, it is almost impossible to provide accurate water vapour estimates from a single satellite instrument or from surface instruments alone. Most of the space borne missions for the exploration of PWV, e.g., TOVS (Television and Infrared Observation Satellite Operational Vertical Sounder) Path-A (Susskind et al. 1997), NASA Water Vapour Project (NVAP) (Randel et al. 1996), NASA Water Vapour Project-Next Generation (NVAPNG) (VonderHaar et al. 2001), etc. exploit only one measurement system (i.e., single source data sets) with NVAP, being an exception. Advanced TOVS (ATOVS) and several microwave radiometers [e.g., Special Sensor Microwave Imager (SSM/I) and Advance Microwave Sounding Unit $\mathrm{A} / \mathrm{B}$ (AMSU-A/B)] have been incorporated into NVAP to make the data set more suitable for atmospheric circulation model evaluation (Schulz and Selbach 2004).

Due to the poor spatial resolution in humidity measurements by satellite platforms, the need to validate their esti- mates using standard in situ data is imperative. Studies have shown that radiosonde and satellite precipitable water vapour profiles correlate well. However, potential errors such as biases that may degrade this relationship do exist. For instance, Schluessel and Emery (1990), using collocation criteria of $\pm 3 \mathrm{hrs}$ and $0.5^{\circ}$ latitude and longitude, carried out initial comparison of instantaneous SSM/I total column water vapor retrievals with those of globally distributed radiosondes for the month of July 1987 and found a wet bias of $0.3 \mathrm{~kg} \mathrm{~m}^{-2}$. This result was corroborated by Schulz et al. (1993), who used August 1987 data, and observed a wet bias of $0.4 \mathrm{~kg} \mathrm{~m}^{-2}$, attributable to the long response time of humidity sensors in the lower altitudes (Soden and Lanzante 1996) as they ascend the atmosphere.

While evaluating the quality of operational radiosonde sensors, using ATOVS data, Moradi et al. (2013) observed that most of the sensors used in the study had a systematic dry bias because of sensors failure in responding to humidity changes in the upper and sometimes, in the middle troposphere. This dry bias is, probably, due to the contamination of the humidity sensors by chemical substances (Miloshevich et al. 2004), longtime instability of the sensor polymer (Wang et al. 2002; Miloshevich et al. 2004) and/or time-lag error (Soden and Lanzante 1996).

Time-dependent positive bias has also been reported. For instance, Schulz et al. (2009) validated the ATOVS humidity products using 173 global radiosonde stations, during which they found positive bias of values between 1 and $2 \mathrm{~kg} \mathrm{~m}^{-2}$, with the tendency of higher biases in the Northern hemisphere summer months.

Changes in the Infrared (IR) surface emissivity are a major culprit in the retrieval of total precipitable water vapour using an IR window channel, with the lower layer humidity profile being the greatest victim. For instance, Bennartz et al. (2008) have found that retrievals of total column water vapour using IR window channels have a respective sensitivity of 0.6 and $2 \mathrm{~kg} \mathrm{~m}^{-2}$ emissivity change in the two HIRS window channels.

It is worth noting that most of the global comparison between radiosonde- and satellite-derived humidity profiles, have been carried out on selected stations without specific representation of the current study area.

The principal objective of this paper, therefore, is to study the variation of total precipitable water vapour, hereafter, WST as well as layered precipitable water vapour, after now, W over Peninsular Malaysia using data retrieved from ATOVS on-board National Oceanic and Atmospheric Administration (NOAA) and European Organization for the Exploitation of Meteorological Satellites (UEMETSAT) satellites. The retrieved data will be compared to radiosonde data extracted over three stations representing the main climatic regions of Peninsular Malaysia. The study area was selected because of the high amount of atmospheric water vapour experienced, mainly due to the high evaporation 
rates alluded to the prevailing monsoons that exhibit seasonal changes within the region. More so, it is an area of relatively homogeneous observations in which the records of changes are available. Surprisingly, however, studies in the literature, particularly, on the observed annual cycle of layered precipitable water vapour over the region are near non-existent, at least as far as our search.

It is, therefore, hoped that this will not only add to the literature, but be of benefit to the Government of Malaysia, particularly, if data from the radiosonde systems, which have high operational cost, can be replaced with reliable satellite-derived data. This study is organized with a brief description of the site in section 2 , followed by a presentation of the satellite and radiosondes data in section 3 . Results are presented and discussed in sections 4 and 5 respectively, while conclusions are finally drawn in section 6 .

\section{STUDY AREA}

Peninsular Malaysia $\left(99-105^{\circ} \mathrm{E} ; 1-7^{\circ} \mathrm{N}\right)$ is the western part of Malaysia in Southeast Asia, and is bordered by Thailand, Singapore and Indonesian island of Sumatra in the south, north, and east respectively (Fig. 1). Being a tropical area, the climate is usually hot and humid throughout the year with temperature ranging between 24 and $32^{\circ} \mathrm{C}$ (Wong et al. 2009; Mahmud et al. 2015). Peninsular Malaysia, falls into type $\mathrm{Af}^{1}$ of the Köppen world climate classification system. In this class, rainfall is observed almost all year long with annual values averaging over $1500 \mathrm{~mm}$ (Pidwirny 2006). Based on precipitation, the climate is characterized by two rainy seasons, influenced by the Northeast monsoon (NEM) from November to March and the Southwest Monsoon (SWM) from May to September (Camerlengo and Demmler 1997; Tangang 2001; Lim and Samah 2004; Suhaila and Jemain 2009). Substantial rainfall also occurs in the transitional periods, usually in April and October, between the monsoons (Suhaila and Jemain 2007; Mahmud et al. 2015).

Mountainous topography, coupled with complex continental - maritime interactions, also influence the climate system of the study area. An aggregate of this local topographic pattern with the Asian Monsoon flows, classify Peninsular Malaysia into five local climatic regions, namely: highland (> $400 \mathrm{~m}$ a.s.1.), northwest, west, southwest, and east (Varikoden et al. 2011; Mahmud et al. 2015). However, for this paper, we have adopted four regional climates in the study area for simplicity and more so based on available radiosonde data (see Table 1 ).

\footnotetext{
1 The climate in this classification is controlled by high year-round of insolation and precipitation of intertropical convergence zone (ITCZ), with rising air along trade wind coast. The regions under this class are characterised with constant high-temperature, evenly distributed heavyprecipitation with much cloud cover and high humidity.
}

\section{METHODOLOGY}

Satellite and radiosonde data sets have been collected to achieve the main objective of this study.

\subsection{Satellite Data}

The Precipitable water vapour product, version 001, used in this study is retrieved and archived by the Satellite Application Facility on Climate Monitoring (CM SAF) from ATOVS instruments on board polar-orbiting satellites (NOAA and EUMETSAT). The ATOVS suite of instruments [High Resolution Infrared Radiation Sounder (HIRS), AMSU-A/B, and Microwave Humidity Sounder (MHS)] on NOAA and Meteorological Operational (MetOp) satellites represent infrared spectrometers and microwave radiometers, where the combination of all three instruments contains enough information to infer atmospheric profiles of temperature and specific humidity.

Temperature and water vapour profile retrievals mostly employ the one-dimensional variation technique that uses the variation principle to solve the retrieval problem. CM SAF applies the scheme developed by Li et al. (2000) to TOVS/ATOVS observations. The so-called International ATOVS Processing Package (IAPP) scheme performs an inversion of the radiances to retrieve simultaneously the temperature and humidity profiles, as well as the surface temperature and cloud top pressure and amount. It employs an iterative method that finds the maximum probability solution to a nonlinear retrieval/analysis problem (Adeyemi and Joerg 2012) and can operate on cloud-free or, in some

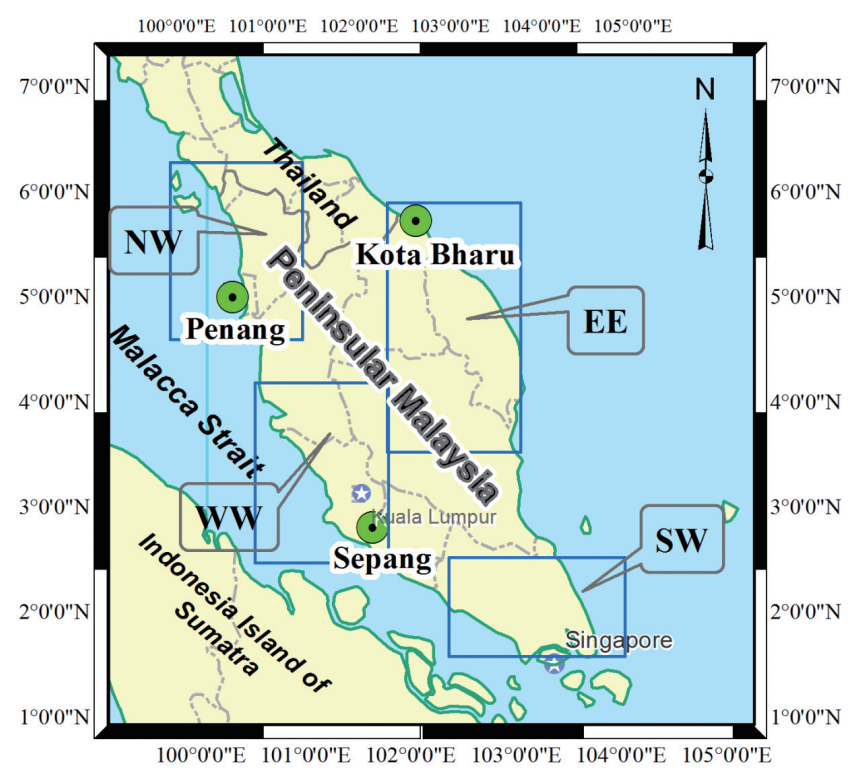

Fig. 1. Study area showing the radiosonde stations at Penang, Kota Bharu, and Sepang, and the four climatic regions - Northwest (NW), East (EE), Southwest (SW), West (WW). (Color online only) 
Table 1. Climatic Regions of the Study Area for the Purpose of this Work.

\begin{tabular}{ccrr}
\hline Climatic Region & Latitude & Longitude & Climate Features \\
\hline EE & $3.24-5.36^{\circ} \mathrm{N}$ & $102.20-104.25^{\circ} \mathrm{E}$ & Tc HRI all year-round; dominated by NEM for 6 months; complex topography \\
SW & $1.08-2.25^{\circ} \mathrm{N}$ & $102.68-103.05^{\circ} \mathrm{E}$ & $\mathrm{Tc} ;$ HRI from April to January of the following year; dominated by SWM for 5 months \\
WW & $2.25-4.64^{\circ} \mathrm{N}$ & $100.81-102.20^{\circ} \mathrm{E}$ & $\mathrm{Tc} ;$ HRI from May to January of the following year; dominated by SWM for 6 months \\
NW & $4.75-6.78^{\circ} \mathrm{N}$ & $100.05-101.25^{\circ} \mathrm{E}$ & $\mathrm{Tc} / \mathrm{Tm}$; HRI from May to December; dominated by SWM for 5 Months \\
\hline
\end{tabular}

Note: Tc - tropical continental; Tm - tropical monsoon; HRI - high rain intensity; EE, SW, WW, NW - east, southwest, west, and northwest regions in that order; NEM - northeast monsoon; and SWM - southwest monsoon.

cases, cloudy radiances. The main satellite data source for the retrieval process depends on the cloudiness of a scene and the underlying surface. Retrievals over oceans rely on all sensors whereas retrievals over land surfaces are mainly based on cloud-free HIRS measurements. The retrieval relies on an a priori background that is given by the 6-hr forecast from the German numerical weather prediction model (Majewski et al. 2002). Global daily fields are constructed using a specific kriging algorithm (Schulz et al. 2009). The daily fields are accompanied by an uncertainty estimate that reflects the retrieval uncertainty and the sampling error, which is particularly important, in tropical areas over land.

Validation activities are routinely performed by the CM SAF, but validation results are only presented in globally averaged numbers. On the global scale, radiosonde- and satellite-derived water vapour agree reasonably well, with systematic differences of $0.5 \mathrm{~kg} \mathrm{~m}^{-2}$ and root-mean-square difference of approximately $4 \mathrm{~kg} \mathrm{~m}^{-2}$ (Adeyemi and Joerg 2012).

CM SAF provides global fields of daily mean vertically integrated water vapour and layered vertically integrated water vapour in five layers (Surface - 850, 850 - 700, 700 - 500, $500-300$, and $300-200 \mathrm{hPa}$ ), hereafter, $\mathrm{W}_{\mathrm{S} 1}, \mathrm{~W}_{\mathrm{S} 2}$, $\mathrm{W}_{\mathrm{S} 3}, \mathrm{~W}_{\mathrm{S} 4}$, and $\mathrm{W}_{\mathrm{S} 5}$, respectively. For this study, data have been extracted from the global products for the entire study area (Fig. 2), covering the period $2001-2011$, and the five layers combined into three isobaric layers to provide compatibility with the in situ data. While precluding the uppermost layer, others were combined as follows: Lower layer $\left(\mathrm{WSL}=\mathrm{W}_{\mathrm{S} 1}\right)$; Middle layer $\left(\mathrm{WSM}=\mathrm{W}_{\mathrm{S} 2}+\mathrm{W}_{\mathrm{S} 3}\right)$; and Upper layer $\left(\mathrm{WSU}=\mathrm{W}_{\mathrm{S} 4}+\mathrm{W}_{\mathrm{S} 5}\right)$. Total precipitable water here, is taken as; WST $=\mathrm{WSL}+\mathrm{WSM}+\mathrm{WSU}$.

\subsection{In Situ Data}

Radiosonde data extracted from the University of $\mathrm{Wy}-$ oming Sounding archives for three stations (see Table 2) were used for the computation of in situ precipitable water vapour in this study. The sounding system at these stations is the Vasaila (RS92G).

The requisite data for calculation of PWV were extracted from twice-daily radiosonde profiles of temperature and moisture, at mandatory and significant levels, at 0000 and 1200 UTC for the period of 2008 - 2011. These meteorological parameters were obtained from the University of Wyoming Sounding archives for World Meteorological Organization (WMO) stations of Penang, Kota Bharu, and Sepang as representatives of their climatic regions in Peninsular Malaysia. The diurnal and nocturnal data were separately treated and found to be highly correlated $(r \geq 0.93)$ within the period of observation. However, the latter was used, mainly because of its homogeneity, since comparison, and not the absolute value of PWV, is the main concern of this study. Moreover, mean monthly PWV could be adequately determined from either 0000 or 1200 UTC (e.g., Hay 1970).

Table 2 gives the station number, code, latitude, longitude and location (also shown in Fig. 1). Using the mean values of the meteorological quantities extracted from the Sonde, the PWV for the Surface - 850, 850 - 700, 700 - 500, $500-400$, and $400-300 \mathrm{hPa}$ layers, subsequently, $\mathrm{W}_{\mathrm{R} 1}$, $\mathrm{W}_{\mathrm{R} 2}, \mathrm{~W}_{\mathrm{R} 3}, \mathrm{~W}_{\mathrm{R} 4}$, and $\mathrm{W}_{\mathrm{R} 5}$, for each station were evaluated from Eq. (2). The layers were combined, for compatibility with the satellite retrieved data, as follows: Lower layer $\left(\mathrm{WRL}=\mathrm{W}_{\mathrm{R} 1}\right)$; Middle layer $\left(\mathrm{WRM}=\mathrm{W}_{\mathrm{R} 2}+\mathrm{W}_{\mathrm{R} 3}\right)$; and $\mathrm{Up}$ per layer $\left(\mathrm{WRU}=\mathrm{W}_{\mathrm{R} 4}+\mathrm{W}_{\mathrm{R} 5}\right)$. The total precipitable water for the in situ measurement was, therefore, taken as; WRT = WRL + WRM + WRU.

Due to poor performance of humidity sensor at cold temperatures and low pressure heights (Elliott and Gaffen 1991; Wang et al. 2003; Free et al. 2004; Trenberth et al. 2005), the uppermost layer was precluded during data processing. Total radiosonde precipitable water for layer bounded by pressures $P_{0}$ and $P$ in $\mathrm{hPa}$, is given by

$\mathrm{WRT}=-\frac{1}{g} \int_{P_{0}}^{P_{z}} r(P) d P$

The practical form of Eq. (1) is expressed as

$\mathrm{WRT}=-\frac{1}{g} \sum_{i=1}^{n}\left(\bar{r}_{i} \Delta P\right)$

$g$ is the gravitational acceleration, $P_{0}$ and $P$ are pressures at 


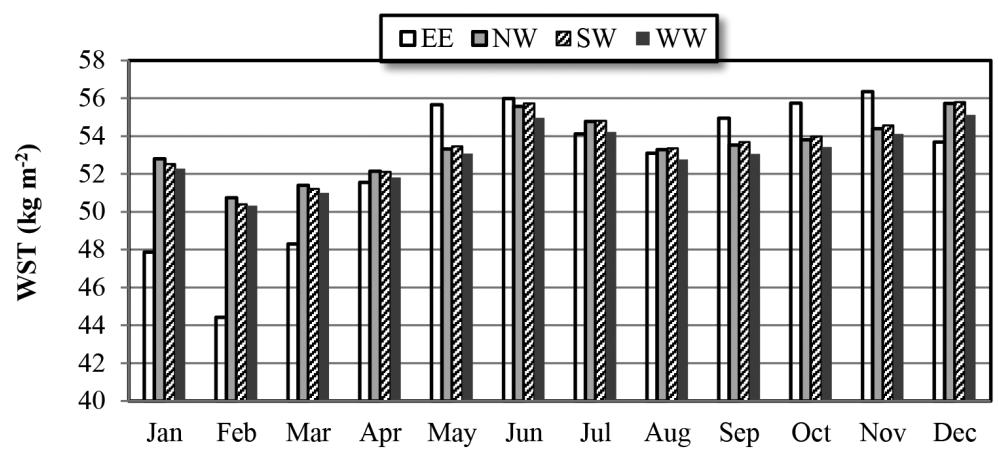

Fig. 2. Monthly variation of total precipitable water vapor (WST) for 2001 - 2011 over the climatic regions of Peninsular Malaysia as retrieved from the CM SAF-ATOVS water vapor product.

Table 2. Selected Radiosonde Stations in Peninsular Malaysia and their Identities.

\begin{tabular}{ccccc}
\hline Station Code/No. & Station Name & Latitude & Longitude & Location \\
\hline WMKP 48601 & Penang & $5.30^{\circ} \mathrm{N}$ & $100.26^{\circ} \mathrm{E}$ & $\mathrm{NW}$ \\
WMKC 48615 & Kota Bharu & $6.16^{\circ} \mathrm{N}$ & $102.28^{\circ} \mathrm{E}$ & EE \\
WMKS 48650 & Sepang & $2.71^{\circ} \mathrm{N} ;$ & $101.70^{\circ} \mathrm{E}$ & WW \\
\hline
\end{tabular}

earth surface and height, $Z$ and $r$ is the mixing ratio given in Eq. (3)

$r=0.622 e_{0} /\left(P-e_{0}\right)$

$e_{0}(\mathrm{hPa})$ is vapour pressure, which is given in Eq. (4)

$e_{0}=e_{s} H / 100$

$H$ is relative humidity and $e_{s}$, the saturation vapor pressure (hPa), expressed in Eq. (5)

$e_{s}=0.611 \exp [17.27 t /(237.3+t)]$

$t$ is air temperature in ${ }^{\circ} \mathrm{C}$.

\section{RESULTS}

\subsection{Variations of Total and Layered Precipitable Water Vapour}

The annual cycle and variation of total precipitable water vapour, WST over the four climatic regions of Peninsular Malaysia are depicted in Fig. 2, from which, WST is observed to exhibit bimodal oscillation in all the zones, with a pair of minima and maxima each. The primary minimum is observed in February throughout the study area. This period is characterised by the lowest amount of rainfall in the Peninsular (see Gaffen et al. 1992; Wong et al. 2009). The value of WST in the study area is observed to increase from February, and persists until May, culminating with a peak in June, marking the secondary maximum in all the climatic regions. It is worth noting that May and November are the beginnings of the SWM and the NEM.

The value of WST experiences a slight decrease from the respective secondary maxima and witnesses its secondary minimum in August over all the climatic regions of the Peninsular, which coincide with the second period of low rainfall. Between July and September, the entire Peninsular experiences period of low precipitation with a minimum in August. The primary maximum value occurs in November, coinciding with the second peak period of precipitation in the study area, usually in October/November. Generally, except for the different values of WST observed for each of the regions, its oscillations are in phase throughout the regions. The highest and lowest primary and secondary maxima as well as their corresponding minimum values are recorded in the EE and WW respectively. It is noted that both the primary maximum and minimum occur during the NEM period of November to March.

Although the climate of Peninsular Malaysia is generally classified as Af, under the Koppen climate classification, other features such as complex topography, local circulations and vegetation cover, which manifest differently in the adopted regions, may contribute to the various mean annual WST values observed across Peninsular Malaysia. For instance, the value of the WST (see Fig. 2) is observed to be higher at EE compared to the values obtained in other regions, which are basically, located on the west coast of the 
study area, particularly at the onset of the NEM. However, at its retreat, between January and March, the EE region presents a lower value of the parameter as against relatively higher values obtained elsewhere. This region, which is located on the east coast of Peninsular Malaysia, is exposed to intense precipitation that is usually unleashed during the NEM period. Also, around July, midway into the SWM, the $\mathrm{NW}, \mathrm{SW}$, and WW regions record relatively higher values of the parameter than the EE region. The values of WST observed in NW, SW and WW do not show marked differences because these regions are dominated by the SWM, which is the drier of the two seasons.

Figures $3 \mathrm{a}-\mathrm{d}$ shows the annual distribution of mean layered precipitable water vapour, $\mathrm{W}$ over the respective climatic regions of Peninsular Malaysia. In all the climatic regions, WSM displays similar characteristics with those of WST. Although WSL also exhibits double oscillations, the primary minimum, which occurred in February for the WST, is observed to span from January to February at all the climatic regions. Also, the primary and secondary maxima, though not conspicuous, are noticed almost at the reverse periods of WST and WSM in all the climatic regions. Except for the primary maximum and minimum, WSL lacks consistent annual cycle in all the regions. WSU has low constant values in all the regions throughout its annual cycle except during the inter-monsoonal periods, when high pre- cipitation ensues, that slight increases are discernible.

\subsection{Comparison Between Satellite and Radiosonde Data}

To our knowledge, there were no instrument changes during the study period, therefore, data from different sensors are not mixed up while calculating statistics for different stations. Least square method was adopted for the comparison between PWV estimates derived from satellite and in situ measurements at the seasonal scale. For compatibility, the daily values of the satellite estimates, for the period 2001 - 2011, were averaged over monthly mean to correspond to the sonde data as earlier mentioned in section 2 .

Comparison of PWV between the two sources of data is depicted in Fig. 4, and the statistical indices displayed in Table 3. High correlation, $r$ exists between $W_{S}$ and $W_{R}$ at all the layers over all the available stations, with values between 0.60 and 0.98 (see Table 3). The regressions obtained are significant at $\alpha_{0.05}$ for all the layers and over all the stations, with coefficients of determination $\left(\mathrm{R}^{2}\right)$, ranging between 0.37 and $0.97 . \mathrm{W}_{\mathrm{S}}$ has been found to be larger than $\mathrm{W}_{\mathrm{R}}$ at the middle and upper isobaric layers with high standard deviations over all the stations except at Kota Bharu, where the trend is reversed at the upper layer during NEM. However, at the lower layer, in all the stations, $W_{R}$ was found to be larger than $\mathrm{W}_{\mathrm{S}}$. The comparisons between
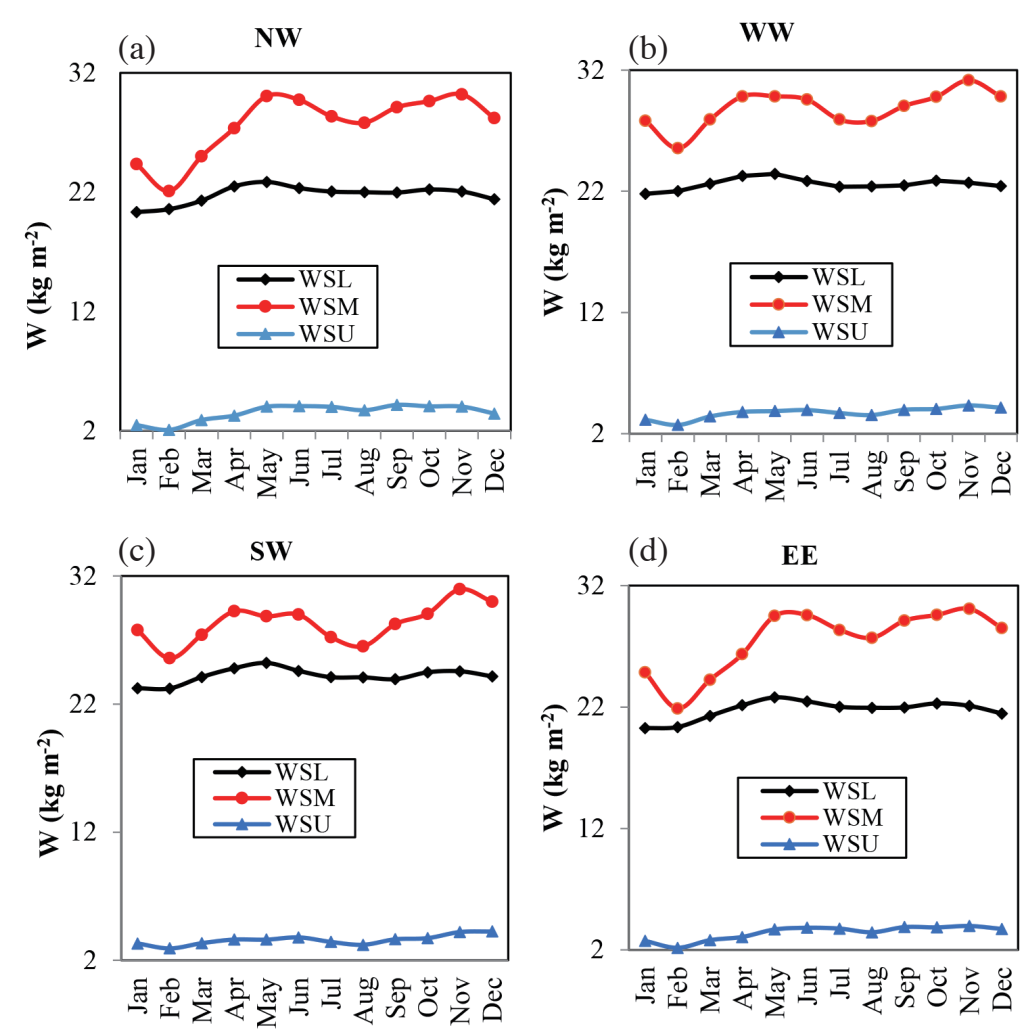

Fig. 3. Monthly distribution of layered precipitable water vapor for 2001 - 2011 (a) NW, (b) WW, (c) SW, and (d) EE regions of Peninsular Malaysia from CM SAF-ATOVS water vapor products. (Color online only) 


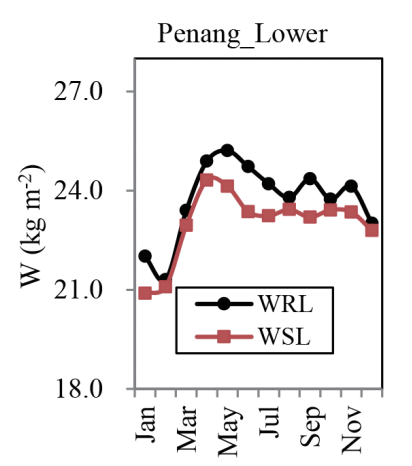

Kota Bharu Lower

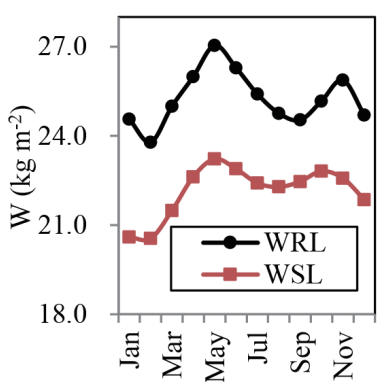

Sepang_Lower

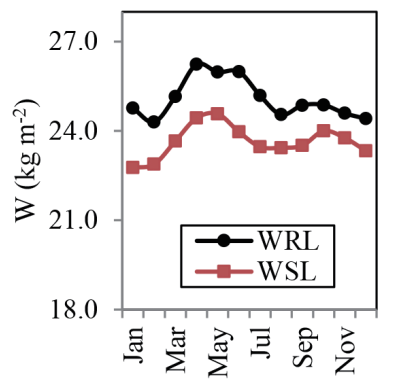

Penang Middle

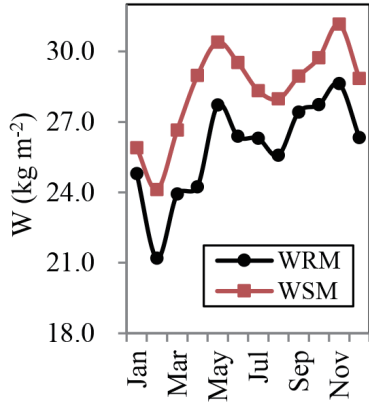

Kota Bharu_Middle

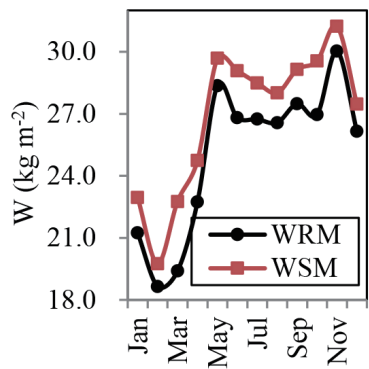

Sepang_Middle

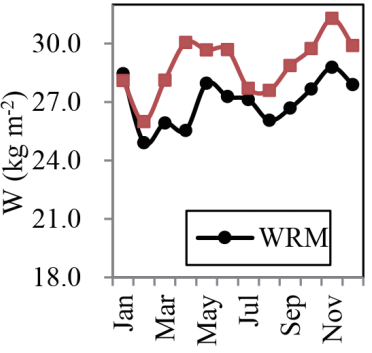

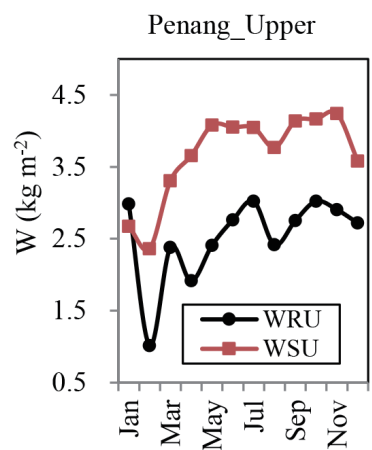

Kota Bharu_Upper
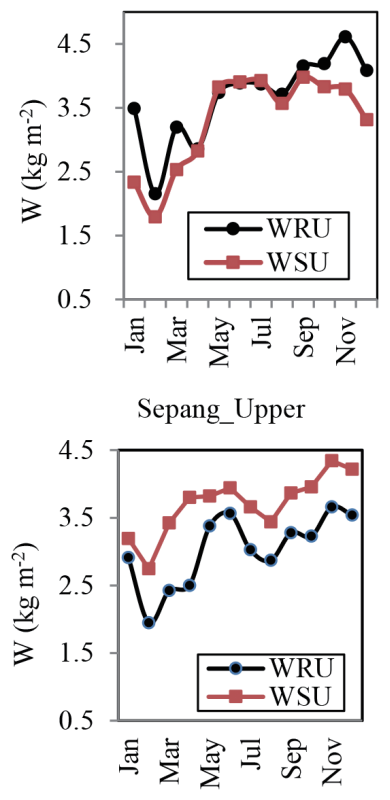

Fig. 4. Comparison between $\mathrm{W}_{\mathrm{S}}$ and $\mathrm{W}_{\mathrm{R}}$ over Peninsular Malaysia using only stations with available radiosonde data. The top, middle and bottom panels are for Penang, Kota Bharu, and Sepang respectively. (Color online only)

Table 3. Regression of $\mathrm{W}_{\mathrm{S}}$ and $\mathrm{W}_{\mathrm{R}}$ at all the isobaric layers, showing values of best-fit parameters, $\alpha$ and $\beta$ (i.e., $\mathrm{W}_{\mathrm{S}}=\alpha+\beta \mathrm{W}_{\mathrm{R}}$ ).

\begin{tabular}{|c|c|c|c|c|c|c|c|}
\hline Station & $\alpha\left(\mathrm{kg} \mathrm{m}^{-2}\right)$ & $\beta\left(\mathrm{kg} \mathrm{m}^{-2}\right)$ & $\mathrm{SE}\left(\mathrm{kg} \mathrm{m}^{-2}\right)$ & $R^{2}$ & $r$ & MB $\left(\mathrm{kg} \mathrm{m}^{-2}\right)$ & p-value \\
\hline \multicolumn{8}{|c|}{ Lower } \\
\hline Penang & 3.08 & 0.840 & 0.01 & 0.88 & 0.94 & -0.52 & 0.000 \\
\hline Kota Bharu & 3.21 & 0.750 & 0.19 & 0.62 & 0.79 & -0.48 & 0.002 \\
\hline Sepang & 7.27 & 0.653 & 0.16 & 0.62 & 0.79 & -0.60 & 0.002 \\
\hline \multicolumn{8}{|c|}{ Middle } \\
\hline Penang & 6.06 & 0.863 & 0.13 & 0.81 & 0.90 & 0.45 & 0.000 \\
\hline Kota Bharu & 3.21 & 0.944 & 0.05 & 0.97 & 0.98 & 0.58 & 0.000 \\
\hline Sepang & 9.09 & 0.733 & 0.30 & 0.38 & 0.62 & 0.59 & 0.032 \\
\hline \multicolumn{8}{|c|}{ Upper } \\
\hline Penang & 2.06 & 0.638 & 0.27 & 0.37 & 0.60 & 0.41 & 0.037 \\
\hline Kota Bharu & -0.14 & 0.940 & 0.19 & 0.71 & 0.84 & -0.18 & 0.001 \\
\hline Sepang & 1.52 & 0.721 & 0.14 & 0.72 & 0.85 & 0.49 & 0.000 \\
\hline
\end{tabular}

Note: $\alpha$ and $\beta$ are parameter estimates, SE is the standard error, MB is mean bias, $R^{2}$ is the coefficient of determination, $r$ is the Pearson product-moment correlation coefficient, and $p$ is a probability value. 
satellite and radiosonde measurements for all the stations at all the isobaric layers, indicate that $\mathrm{W}_{\mathrm{R}}$ is larger than $\mathrm{W}_{\mathrm{S}}$ at the lower layer with scale-factors ${ }^{2}$ of $0.840 \pm 0.10,0.750 \pm$ 0.19 , and $0.653 \pm 0.16$ at Penang, Kota Bharu, and Sepang respectively. However, at both the middle and upper layers in all the stations, $\mathrm{W}_{\mathrm{S}}$ is larger than $\mathrm{W}_{\mathrm{R}}$, except at the upper layer for Kota Bharu, particularly during the NEM season with scale-factors of $0.863 \pm 0.13$ at Penang; $0.944 \pm 0.05$ at Kota Bharu; $0.733 \pm 0.30$ at Sepang for the middle layer and $0.638 \pm 0.27,0.940 \pm 0.19,0.721 \pm 0.14$ for Penang, Kota Bharu, and Sepang respectively, at the upper layer.

In terms of bias, the lower layer in all the stations showed respective wet mean bias of $-0.52,-0.48$, and $-0.60 \mathrm{~kg} \mathrm{~m}^{-2}$ for Penang, Kota Bharu, and Sepang (see Fig. 5; Table 3). However, at the middle and upper layers, dry mean bias was observed in all the stations, except for the upper layer at Kota Bharu, where a wet bias was noted. Penang, Kota Bharu, and Sepang presented mean bias of $0.45,0.58$, and $0.59 \mathrm{~kg} \mathrm{~m}^{-2}$ at the middle and $0.41,-0.18$, and $0.49 \mathrm{~kg} \mathrm{~m}^{-2}$ at the upper layer respectively. A combined mean bias for the three stations, representing the climatic regions of Peninsular Malaysia, also showed a wet bias of $-0.53 \mathrm{~kg} \mathrm{~m}^{-2}$ at the lower layer, and a dry mean bias of 0.56 and $0.24 \mathrm{~kg} \mathrm{~m}^{-2}$ at the middle and upper tropospheric layers respectively.

These results are comparable to those of Courcoux and Schröder (2015), who obtained wet and dry biases of -0.7 and $0.6 \mathrm{~kg} \mathrm{~m}^{-2}$ respectively, at the lower and middle layers of the troposphere, while comparing humidity products from ATOVS with those of the Global Climate Observing System (GCOS) Upper-Air Network (GUAN) radiosondes.

Figure 6 presents the scatter-plots and least square regression lines of the difference in PWV $\left(\mathrm{W}_{\mathrm{D}}=\mathrm{W}_{\mathrm{S}}-\mathrm{W}_{\mathrm{R}}\right)$ against $\mathrm{W}_{\mathrm{S}}$ at the different layers and for the three stations that had radiosonde data. The top panel (Penang station) shows there are no correlations between $\mathrm{W}_{\mathrm{D}}$ and $\mathrm{W}_{\mathrm{S}}$ at both the lower and middle layers, though a weak correlation $r=$ 0.49 is observed at the upper layer (i.e., at the upper layer, the difference between $\mathrm{W}_{\mathrm{S}}$ and $\mathrm{W}_{\mathrm{R}}$ tends to increase as the value of $\mathrm{W}_{\mathrm{S}}$ increases). The middle panel (Kota Bharu) indicates the absence of correlation between $\mathrm{W}_{\mathrm{D}}$ and $\mathrm{W}_{\mathrm{S}}$, particularly at the lower and middle layers, while a weak relationship $(r=0.46)$ is observed at the upper layer over the station. The slight increases observed, when $\mathrm{W}_{\mathrm{D}}$ was regressed against $\mathrm{W}_{\mathrm{S}}$ (see Fig. 6), particularly at the Penang and Kota Bharu stations, may not be unconnected with a systematic dry bias (Moradi et al. 2013) suffered by humidity sensor while probing the upper troposphere. At Sepang (bottom panel) an increasing relationship, with $r=0.59$ is

\footnotetext{
2 The ratios of the regression coefficients, when radiosonde precipitable water vapour $\left(W_{R}\right)$ was regressed on its satellite $\left(W_{S}\right)$ counterpart, for each of the isobaric layers.
}

noticed at the middle layer without any discernible relationship between $\mathrm{W}_{\mathrm{D}}$ and $\mathrm{W}_{\mathrm{S}}$ at both the lower and upper layers. Generally, except for the middle layer for Sepang, the upper layers for Penang and Kota Bharu, where weak increasing tendencies were noticed, all the stations presented relatively uniform $W_{D}$ for all the isobaric layers, irrespective of the variations in the value of $\mathrm{W}_{\mathrm{S}}$, and to a large extend, the period of the year. The uniform value of $\mathrm{W}_{\mathrm{D}}$ observed indicate compatibility between the satellite and radiosonde derived precipitable water.

Studies have shown that there are seasonal differences in the quality of relative humidity measurements by radiosondes. For instance, Peixoto and Oort (1996), who studied the climatology of relative humidity in the atmosphere based on global radiosonde data, have observed these differences. Also, Balogun and Adedokun (1986) and Olaniran and Sumner (1989) have confirmed such differences over West Africa. Four seasons: NEM, pre-monsoon, SWM, and early NEM have been identified for Peninsular Malaysia (Varikoden et al. 2011). However, just for the purpose of this study, we have compared the estimated water vapour from the two sources on a seasonal scale by separating $\mathrm{W}_{\mathrm{S}}$ and $\mathrm{W}_{\mathrm{R}}$ into NEM and SWM (see Table 4).

During the NEM linear relationship between $\mathrm{W}_{\mathrm{S}}$ and $\mathrm{W}_{\mathrm{R}}$, with high correlation coefficients, were obtained at the lower and middle layers for Penang and at all layers for Kota Bharu. However, only the upper layer at Sepang exhibited a linear relationship, and other layers were not significant (see Table 4). During SWM, correlations were observed only at the lower layer at Kota Bharu and the upper layer at Sepang, while all other layers at all the stations showed insignificant relationships. Comparing the radiosonde measurements of PWV to those from satellite source, a change in bias (see Fig. 5) from a low value range of $0.12-1.30 \mathrm{~kg} \mathrm{~m}^{-2}$ at Kota Bharu during the drier season of SWM to a slightly higher value range of $0.21-2.41 \mathrm{~kg} \mathrm{~m}^{-2}$ at the same station during the wetter season of NEM was observed.

\section{DISCUSSION}

The inconsistent behaviour of WSL with respect to WST and WSM may be attributed to a number of reasons, such as, the deteriorating ability of satellite in retrieving humidity profiles near the surface compared to the middle troposphere (Gruber and Watkins 1982). Changes in the surface emissivity (Bennartz et al. 2008) may also contribute to the observed inconsistency. It is also likely that such inconsistency may result from the interference of topography (Schulz et al. 2009), a general feature of the study area, with the prevailing circulation aloft. The bimodal oscillations of WST and W exhibit phase semblance with the findings of Wong et al. (2009), for precipitation in Peninsular Malaysia and those of Olaniran and Sumner (1989) and Adeyemi (2009), using radiosonde data taken over the coastal region of West Africa. 

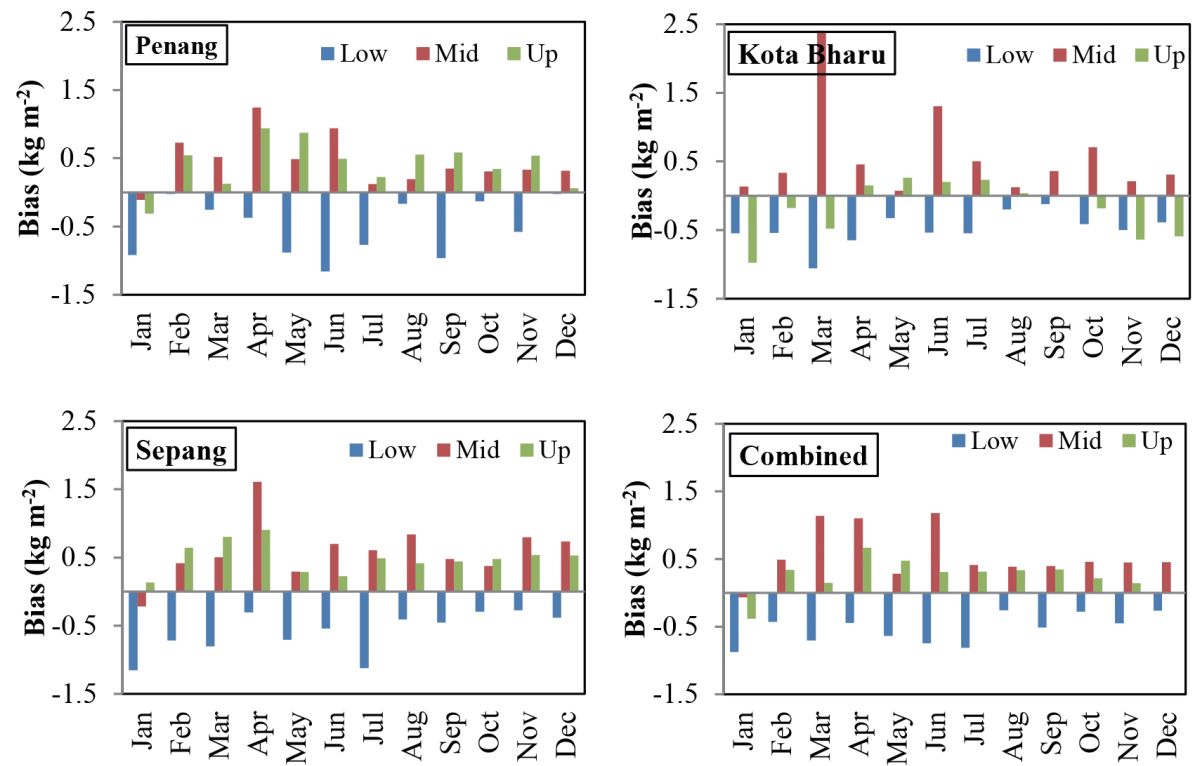

Fig. 5. Bias between the satellite and radiosonde monthly mean layered precipitable water vapor for the radiosonde stations of Penang, Kota Bharu, and Sepang. The lower panel (right), shows the bias for the combined stations. (Low, Mid, and Up represent lower, middle, and upper isobaric layers respectively). (Color online only)
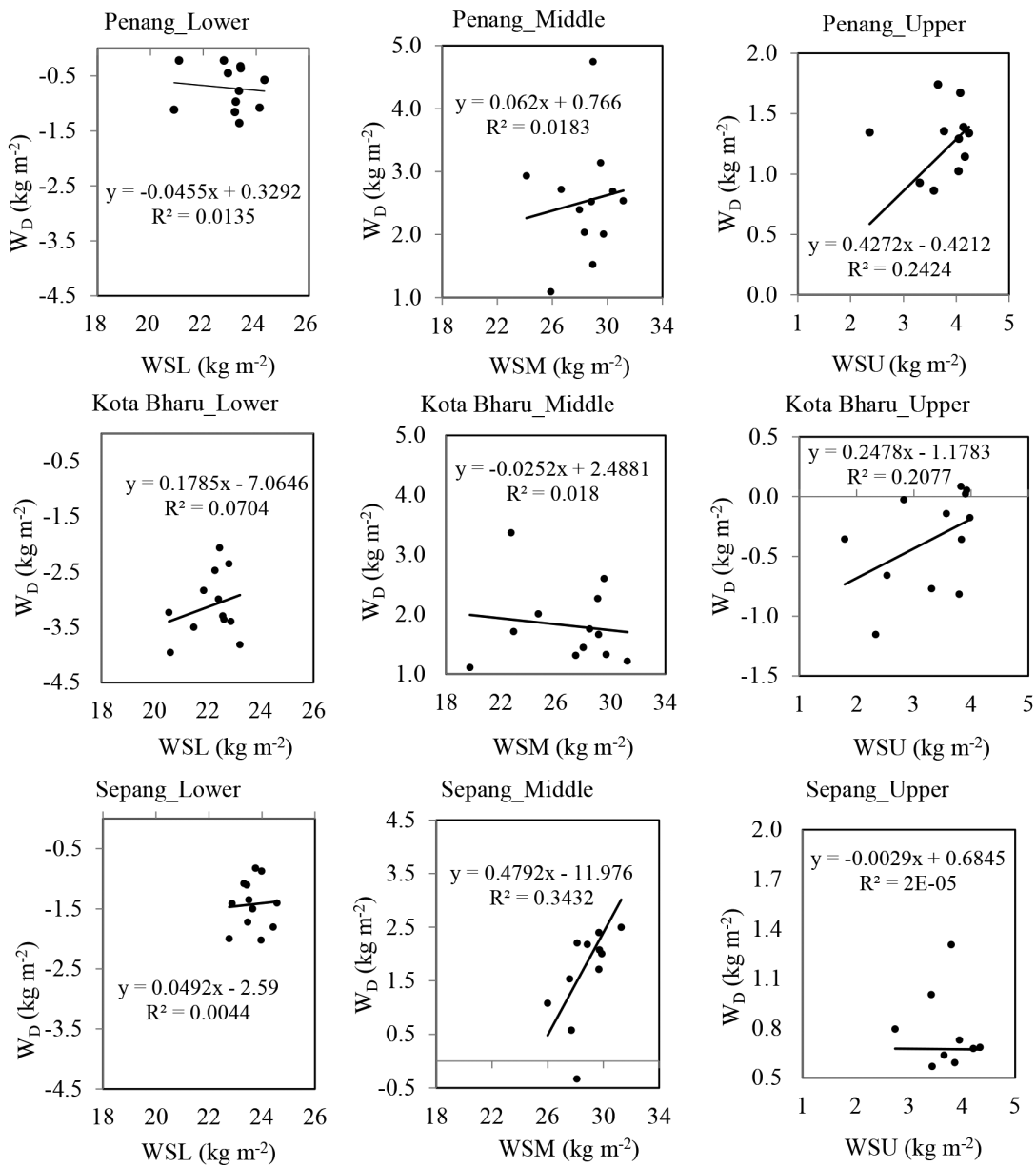

Fig. 6. Scatter-plots and least square regression lines of difference in $W\left(W_{D}=W_{S}-W_{R}\right)$ against $W_{S}$ for Penang, Kota Bharu, and Sepang are shown at the top, middle, and bottom panels respectively. 
Table 4: Same as Table 3, but for NEM, SWM, and Remark.

\begin{tabular}{|c|c|c|c|c|c|c|c|}
\hline Station & Season & $\alpha$ & $\beta$ & SE & $R^{2}(\%)$ & p-value & Remark \\
\hline \multicolumn{8}{|c|}{ Lower } \\
\hline \multirow{2}{*}{ Penang } & NEM & 0.44 & 0.956 & 0.20 & 0.89 & 0.017 & S \\
\hline & SWM & 11.14 & 0.504 & 0.29 & 0.51 & 0.176 & NS \\
\hline \multirow{2}{*}{ Kota Bharu } & NEM & -3.37 & 1.000 & 0.31 & 0.77 & 0.050 & S \\
\hline & SWM & 13.74 & 0.348 & 0.08 & 0.84 & 0.019 & $S$ \\
\hline \multirow{2}{*}{ Sepang } & NEM & 10.81 & 0.506 & 0.71 & 0.15 & 0.526 & NS \\
\hline & SWM & 7.82 & 0.631 & 0.23 & 0.72 & 0.071 & NS \\
\hline \multicolumn{8}{|c|}{ Middle } \\
\hline \multirow{2}{*}{ Penang } & NEM & 3.55 & 0.952 & 0.15 & 0.93 & 0.008 & S \\
\hline & SWM & 6.11 & 0.859 & 0.40 & 0.61 & 0.121 & NS \\
\hline \multirow{2}{*}{ Kota Bharu } & NEM & 3.72 & 0.914 & 0.10 & 0.97 & 0.003 & S \\
\hline & SWM & 8.24 & 0.759 & 0.25 & 0.76 & 0.055 & NS \\
\hline \multirow{2}{*}{ Sepang } & NEM & 2.19 & 0.974 & 0.39 & 0.67 & 0.090 & NS \\
\hline & SWM & 0.61 & 1.040 & 0.56 & 0.52 & 0.168 & NS \\
\hline \multicolumn{8}{|c|}{ Upper } \\
\hline \multirow{2}{*}{ Penang } & NEM & 1.85 & 0.574 & 0.42 & 0.39 & 0.262 & NS \\
\hline & SWM & 3.34 & 0.255 & 0.28 & 0.22 & 0.431 & NS \\
\hline \multirow{2}{*}{ Kota Bharu } & NEM & -0.11 & 0.817 & 0.14 & 0.92 & 0.011 & S \\
\hline & SWM & 2.29 & 0.057 & 0.12 & 0.06 & 0.671 & NS \\
\hline \multirow{2}{*}{ Sepang } & NEM & 1.05 & 0.875 & 0.20 & 0.87 & 0.021 & S \\
\hline & SWM & 1.55 & 0.682 & 0.13 & 0.90 & 0.015 & $\mathrm{~S}$ \\
\hline
\end{tabular}

Note: *: $S$ and NS represent significant and not significant probability value at 0.05-alpha level.

The NW, WW, and SW experience two rainy seasons, which are fairly distinguishable during the inter-monsoonal periods of March to April and October to November, when substantial precipitation, linked with the reversal of the wind directions as well as the influence of local topography in the regions ensues. The primary and secondary minima of both WST and W respectively coincide with the retreat of the SWM and NEM, while their maxima counterparts coincide with the onset of NEM and SWM. The dip in precipitation during these periods may be due to several factors such as coastal upwelling and circulation aloft, which becomes divergent and subsident as a result of the frequent occurrence of inversions and isothermals in the upper atmosphere along the coast (Olaniran and Sumner 1989; Willoughby et al. 2002). WSM is observed to be higher than WSL in all the climatic regions. This may be attributed to a dynamic effect such as the lifting of the boundary layer, whereby persisting surface heating of the lowest layer of the atmosphere causes surface air to acquire additional kinetic energy, making it less dense and more buoyant, resulting in the upward transport of water vapour, hence its depletion at the lower layer.

The differences observed, when precipitable water from the two sources of measurement were compared on a seasonal basis, may be attributed to many causes, some of which are easily noticeable while a lot more are hardly discernible. Although the radiosonde data obtained for Peninsular Malaysia in this study are relatively homogeneous, there were, however, a few temporal gaps at almost all the stations considered. For good quality assurance, the data at all the stations were pruned via a series of averaging and re-averaging, which could have resulted in the differences noted. Smout et al. (2001) and Liu and Tang (2014) have reported that humidity sensors respond poorly when they are heated up, leading to underestimation of relative humidity than expected, particularly during the ascend of radiosonde through stratified clouds with high moisture content. This, perhaps, explains the fairly large bias variation observed at Kota Bharu, during the SWM (drier and hotter of the two seasons under consideration), which may not be entirely attributed to natural or artificial variability of the atmosphere, but also to the failure of humidity sensors. Note that Kota Bharu is on the EE region of Peninsular Malaysia, which is exposed to cloudless skies during the SWM period (Camerlengo and Demmler 1997). The wet bias observed at the lower troposphere in all the stations may be linked to a time-lag response (Schluessel and Emery 1990; Soden and Lanzante 1996) by humidity sensors as they ascend the atmosphere. On the other hand, the dry bias observed at both the middle and lower isobaric layers may be attributed to contamination (Miloshevich et al. 2004) or unstable polymer (Wang et al. 2002) in the instrument's sensors, leading to an impaired response to humidity at these altitudes (Moradi et al. 2013).

The satellite-derived data are not absolved from the causes of the differences noticed, particularly in the study 
area. The ATOVS observing system and the associated retrieval scheme use different sensor combinations over land and ocean and only for cloud-free HIRS observations (Li et al. 2000; Schulz et al. 2009). The use of only infrared (IR) measurements, applying the differential absorption in the atmospheric window channels (11.11 and $12.47 \mu \mathrm{m})$ while employing directly, the absorption features in the water vapour channels ( 6.52 and $7.33 \mu \mathrm{m})$, impedes the information content regarding the trend of the lower and upper layers to the extent that the middle layer is almost left with little or no information. This information gap becomes increasingly blurred when the atmosphere becomes more humid, since the peaks of the water vapour channels are high up in the atmosphere.

Also, changes in the IR surface emissivity can strongly influence the retrieval of the layer averaged water vapour contents. Bennartz et al. (2008) have shown that retrievals of total column water vapour using IR window channels have respective sensitivity of 0.6 and $2 \mathrm{~kg} \mathrm{~m}^{-2}$ emissivity change in the two HIRS window channels. Using available IR emissivity databases, Bennartz et al. (2008) have shown that the variability of surface emissivity in the window channels is almost $1 \%$, leading to uncertainties on the order of the sensitivity in the window channels. The Li et al. (2000) retrieval, as employed in CM SAF, uses a constant surface emissivity (0.99) for the window channels. Such small deviations from this value can, therefore, lead to large changes in the lower layer water vapour estimates. The Seemann et al. (2008) emissivity database shows that the emissivity in the IR channels varies with changing vegetation cover, which is not considered in the satellite retrieval scheme.

Bennartz et al. (2008) also showed that iterative retrievals over land may introduce large artificial daily variations in retrieved column water vapour that were negatively correlated with surface temperature. This is caused by the background and its error covariance in the retrieval that do not match the local conditions. In the presented comparison, the satellite observations are taken under very different surface temperature conditions.

Another cause for the differences observed, between the satellite retrieved data and its radiosonde counterpart, mostly during the NEM season, may be attributed to the method of comparison used in this study. While the radiosonde PWV is the vertical integration of specific humidity along its flight path, in which the horizontal drift of the instrument is essential, the collocation ( $\mathrm{Li}$ et al. 2003), however, of the instantaneous vertically integrated satellite-derived PWV based on the starting location of the radiosonde, can lead to very large differences, especially for the upper layer water vapour estimate.

\section{CONCLUSION}

The annual cycle of total precipitable water vapour, as retrieved from ATOVS on board NOAA and EUMETSAT satellites and archived by CM SAF, Deutscher Wetterdienst, Germany, has been observed to exhibit bimodal oscillations, with a pair of minima and maxima, in all the four climate regions of Peninsular Malaysia. The primary and secondary minima occur in February and August, while their maxima counterparts are observed in October/November and May/ June throughout the study area. This trend is replicated by layered precipitable water vapour, $\mathrm{W}$, except for the upper isobaric layer, whose values are low and almost constant in all the regions. WSM was larger than WSL and WSU. The oscillations of WST and W coincide with the low and high precipitation in the study area (Gaffen et al. 1992; Wang et al. 2003). High correlations ( 0.60 - 0.98$)$ were obtained when $\mathrm{W}_{S}$ was compared with $\mathrm{W}_{\mathrm{R}}$ at each layer in all the regions. The regressions were found to be significant, with a coefficient of determination ranging between 0.37 and 0.97 throughout.

The good agreement between the CM SAF data and its radiosonde counterpart show that the former was a better alternative in areas such as Peninsular Malaysia, where the data paucity of the latter is obvious. While $\mathrm{W}_{\mathrm{S}}$ dominated at the middle and upper layers, the reverse was, however, noticed at the lower layer. At the lower layer $\mathrm{W}_{\mathrm{R}}>\mathrm{W}_{\mathrm{S}}$ with scale factors of $0.840 \pm 0.10,0.750 \pm 0.19$, and $0.653 \pm$ 0.16 at Penang, Kota Bharu, and Sepang respectively. At the middle and upper layers in all the stations, $\mathrm{W}_{\mathrm{S}}>\mathrm{W}_{\mathrm{R}}$, with scale values of $0.863 \pm 0.13$ at Penang; $0.944 \pm 0.05$ at Kota Bharu; $0.733 \pm 0.30$ at Sepang for the middle layer and $0.638 \pm 0.27,0.940 \pm 0.19,0.721 \pm 0.14$ for Penang, Kota Bharu, and Sepang respectively, at the upper layer. These differences may be attributed to dry (Miloshevich et al. 2004; Moradi et al. 2013) or wet (Schulz et al. 1993) bias in the radiosonde humidity measurements.

Mean wet biases of $-0.52,-0.48,-0.60$, and $-0.53 \mathrm{~kg} \mathrm{~m}^{-2}$ for Penang, Kota Bharu, Sepang, and Combined stations, were obtained at the lower layer. However, at the middle layer in Penang, Kota Bharu, Sepang, and Combined stations, mean dry bias of $0.45,0.63,0.59$, and $0.56 \mathrm{~kg} \mathrm{~m}^{-2}$ were respectively observed. Only Kota Bharu presented a wet bias of $-0.18 \mathrm{~kg} \mathrm{~m}^{-2}$ for the upper layer, against the dry bias of $0.41,0.49$, and $0.24 \mathrm{~kg} \mathrm{~m}^{-2}$ obtained at Penang, Sepang, and Combined stations.

At the seasonal level, the difference between precipitable water vapour from the two sources of estimates, $\mathrm{W}_{\mathrm{D}}$, was regressed on $\mathrm{W}_{\mathrm{s}}$. While weak correlations were obtained at the upper layers in Penang and Kota Bharu as well as at the middle layer in Sepang with the respective coefficients of determination being $0.24,0.21$, and 0.35 , other layers in all the regions showed insignificant relationships. i.e., $\mathrm{W}_{\mathrm{D}}$ remained fairly constant, irrespective of increase in the value of $\mathrm{W}_{\mathrm{s}}$. Seasonal effects on data acquisition reveal, in some cases, that discrepancies exist between the two sources of PWV estimates during the Northeast and Southwest monsoon seasons. 
Acknowledgements The authors profoundly appreciate the Management and Officials of CM SAF at Deutscher Wetterdienst, Germany, for providing the satellite data (http:// dx.doi.org/10.5676/EUM SAF CM/WVT ATOVS/V001) used in this study, in NetCDF format. We also acknowledge the University of Wyoming for the radiosonde data retrieved online through http://weather.uwyo.edu.

\section{REFERENCES}

Adeyemi, B., 2009: Empirical Modeling of Layered Integrated Water Vapor Using Surface Mixing Ratio in Nigeria. J. Appl. Meteorol. Climatol., 48, 369-380, doi: 10.1175/2008jamc1929.1. [Link]

Adeyemi, B. and S. Joerg, 2012: Analysis of water vapor over Nigeria using radiosonde and satellite data. J. Appl. Meteorol. Climatol., 51, 1855-1866, doi: 10.1175/JAMC-D-11-0119.1. [Link]

Balogun, E. E. and J. A. Adedokun, 1986: On the variations in precipitable water over some West African stations during the special observation period of WAMEX. Mon. Weather Rev., 114, 772-776, doi: 10 $.1175 / 1520-0493(1986) 114<0772$ :OTVIPW>2.0.CO; 2. [Link]

Bennartz, R., A. Walther, and M. Stengel, 2008: Potential improvements of retrieval methods for total and vertically resolved water vapor content over land surfaces from SEVIRI (DVAP-III and DVAP-IV): Scientific and technical report - final version 2.0. CMSAF Working Contract Report.

Camerlengo, A. L. and M. I. Demmler, 1997: Wind-driven circulation of peninsular Malaysia's eastern continental shelf. Sci. Mar., 61, 203-211.

Chaboureau, J. P., A. Chédin, and N. A. Scott, 1998: Remote sensing of the vertical distribution of atmospheric water vapor from the TOVS observations: Method and validation. J. Geophys. Res., 103, 8743-8752, doi: 10.1029/98jd00045. [Link]

Courcoux, N. and M. Schröder, 2015: The CM SAF ATOVS data record: overview of methodology and evaluation of total column water and profiles of tropospheric humidity. Earth Syst. Sci.Data, 7, 397-414, doi: 10.5194/ essd-7-397-2015. [Link]

Elliott, W. P. and D. J. Gaffen, 1991: On the utility of radiosonde humidity archives for climate studies. Bull. Amer. Meteorol. Soc., 72, 1507-1520, doi: 10.1175/15 20-0477(1991)072<1507:OTUORH >2.0.CO;2. [Link]

Eng, R. S., P. L. Kelley, A. Mooradian, A. R. Calawa, and T. C. Harman, 1973: Tunable laser measurements of water vapor transitions in the vicinity of $5 \mu \mathrm{m}$. Chem. Phys. Lett., 19, 524-528, doi: 10.1016/0009-2614(73)851395. [Link]

Follette-Cook, M. B., R. D. Hudson, and G. E. Nedoluha, 2009: Classification of Northern Hemisphere strato- spheric ozone and water vapor profiles by meteorological regime. Atmos. Chem. Phys., 9, 5989-6003, doi: 10.5194/acp-9-5989-2009. [Link]

Free, M., J. K. Angell, I. Durre, J. Lanzante, T. C. Peterson, and D. J. Seidel, 2004: Using first differences to reduce inhomogeneity in radiosonde temperature datasets. $J$. Climate, 17, 4171-4179, doi: 10.1175/JCLI3198.1. [Link]

Gaffen, D. J., A. Robock, and W. P. Elliott, 1992: Annual cycles of tropospheric water vapor. J. Geophys. Res., 97, 18185-18193, doi: 10.1029/92JD01999. [Link]

Gerding, M., C. Ritter, M. Müller, and R. Neuber, 2004: Tropospheric water vapour soundings by lidar at high Arctic latitudes. Atmos. Res., 71, 289-302, doi: 10.1016/j.atmosres.2004.07.002. [Link]

Gruber, A. and C. D. Watkins, 1982: Statistical assessment of the quality of TIROS-N and NOAA- 6 satellite soundings. Mon. Weather Rev., 110, 867-876, doi: 10 $.1175 / 1520-0493(1982) 110<0867$ :SAOTQO > 2.0.CO; 2. [Link]

Hay, J. E., 1970: Precipitable water over Canada: I Computation. Atmosphere, 8, 128-143.

Held, I. M. and B. J. Soden, 2000: Water vapor feedback and global warming. Annu. Rev. Energ. Environ., 25, 441475, doi: 10.1146/annurev .energy.25.1.441. [Link]

Jacob, D., 2001: The role of water vapour in the atmosphere. A short overview from a climate modeller's point of view. Phys. Chem. Earth Solid Earth Geodes., 26, 523527, doi: 10.1016/S1464-1895(01)00094-1. [Link]

Li, J., W. W. Wolf, W. P. Menzel, W. Zhang, H. L. Huang, and T. H. Achtor, 2000: Global soundings of the atmosphere from ATOVS measurements: The algorithm and validation. J. Appl. Meteorol., 39, 1248-1268, doi: 10.1175/1520-0450(2000)039<1248:GSOTAF > 2.0.C O;2. [Link]

Li, Z., J. P. Muller, and P. Cross, 2003: Comparison of precipitable water vapor derived from radiosonde, GPS, and Moderate-Resolution Imaging Spectroradiometer measurements. J. Geophys. Res., 108, 4651, doi: 10.1029/2003JD003372. [Link]

Lim, J. T. and A. A. Samah, 2004: Weather and Climate of Malaysia, University of Malaya Press.

Liu, Y. and N. Tang, 2014: Humidity sensor failure: a problem that should not be neglected. Atmos. Meas. Tech., 7, 3909-3916, doi: 10.5194/amt-7-3909-2014. [Link]

Mahmud, M. R., S. Numata, H. Matsuyama, T. Hosaka, and M. Hashim, 2015: Assessment of effective seasonal downscaling of TRMM precipitation data in peninsular Malaysia. Rem. Sens., 7, 4092-4111, doi: 10.3390/ rs70404092. [Link]

Majewski, D., D. Liermann, P. Prohl, B. Ritter, M. Buchhold, T. Hanisch, G. Paul, W. Wergen, and J. Baumgardner, 2002: The operational global icosahedralhexagonal gridpoint model GME: Description and 
high-resolution tests. Mon. Weather Rev., 130, 319338, doi: 10.1175/1520-0493(2002)130<0319:TOGIH $\mathrm{G}>2.0 . \mathrm{CO} ; 2$. [Link]

Miloshevich, L. M., A. Paukkunen, H. Vömel, and S. J. Oltmans, 2004: Development and validation of a time-lag correction for Vaisala radiosonde humidity measurements. J. Atmos. Ocean. Technol., 21, 1305-1327, doi: 10.1175/1520-0426(2004)021<1305:davoat>2.0.co;2 . [Link]

Mockler, S., 1995: Water vapor in the climate system. Special Report, American, Geophysical Union.

Moradi, I., B. Soden, R. Ferraro, P. Arkin, and H. Vömel, 2013: Assessing the quality of humidity measurements from global operational radiosonde sensors. J. Geophys. Res., 118, 8040-8053, doi: 10.1002/jgrd.50589. [Link]

Olaniran, O. J. and G. N. Sumner, 1989: A study of climatic variability in Nigeria based on the onset, retreat, and length of the rainy season. Int.J. Climatol., 9, 253-269, doi: 10.1002/joc.3370090304. [Link]

Peixoto, J. and A. H. Oort, 1996: The climatology of relative humidity in the atmosphere. J. Climate, 9, 34433463, doi: 10.1175/1520-0442(1996)009<3443:TCOR $\mathrm{HI}>2.0 . \mathrm{CO} ; 2$. [Link]

Pidwirny, M., 2006: "Climate Classification and Climatic Regions of the World". Fundamentals of Physical Geography, 2nd Edition. Date Viewed 23/11/2016. Available at http://www.physicalgeography.net/ fundamentals $/ 7 \mathrm{v} \cdot \mathrm{html}$.

Randel, D. L., T. J. Greenwald, T. H. Vonder Haar, G. L. Stephens, M. A. Ringerud, and C. L. Combs, 1996: A new global water vapor dataset. Bull. Amer. Meteorol. Soc., 77, 1233-1246, doi: 10.1175/1520-0477(1996)077<1233:angwvd>2.0.co;2. [Link]

Schluessel, P. and W. J. Emery, 1990: Atmospheric water vapour over oceans from SSM/I measurements. Int. J. Remote Sens., 11, 753-766, doi: 10.1080/01431169008955055. [Link]

Schulz, J. and N. Selbach, 2004: The SAF on Climate Monitoring: The Humidity Composite Product.

Schulz, J., P. Schluessel, and H. Grassl, 1993: Water vapour in the atmospheric boundary layer over oceans from SSM/I measurements. Int. J. Remote Sens., 14, 27732789, doi: 10.1080/01431169308904308. [Link]

Schulz, J., P. Albert, H. D. Behr, D. Caprion, H. Deneke, S. Dewitte, B. Dürr, P. Fuchs, A. Gratzki, P. Hechler, R. Hollmann, S. Johnston, K.-G. Karlsson, T. Manninen, R. Müller, M. Reuter, A. Riihelä, R. Roebeling, N. Selbach, A. Tetzlaff, W. Thomas, M. Werscheck, E. Wolters, and A. Zelenka, 2009: Operational climate monitoring from space: the EUMETSAT Satellite Application Facility on Climate Monitoring (CM-SAF). Atmos. Chem. Phys., 9, 1687-1709, doi: 10.5194/acp9-1687-2009. [Link]
Seemann,S.W.,E.E. Borbas, R. O.Knuteson, G.R. Stephenson, and H. L. Huang, 2008: Development of a global infrared land surface emissivity database for application to clear sky sounding retrievals from multispectral satellite radiance measurements. J. Appl.Meteorol.Climatol., 47, 108-123, doi: 10.1175/2007JAMC1590.1. [Link]

Smout, R., J. Elms, D. Lyth, and J. Nash, 2001: Met Office RS90 Pressure Sensor Evaluations. New Technology in Upper-air Observations Report.

Soden, B. J. and J. R. Lanzante, 1996: An assessment of satellite and radiosonde climatologies of upper-tropospheric water vapor. J. Climate, 9, 1235-1250, doi: 10.1175/1520-0442(1996)009<1235:aaosar>2.0.co;2. [Link]

Suhaila, J. and A. A. Jemain, 2007: Fitting daily rainfall amount in Malaysia using the normal transform distribution. J. Appl. Sci., 7, 1880-1886, doi: 10.3923/ jas.2007.1880.1886. [Link]

Suhaila, J. and A. A. Jemain, 2009: Investigating the impacts of adjoining wet days on the distribution of daily rainfall amounts in Peninsular Malaysia. J. Hydrol., 368, 17-25, doi: 10.1016/j.jhydrol.2009.01.022. [Link]

Susskind, J., P. Piraino, L. Rokke, L. Iredell, and A. Mehta, 1997: Characteristics of the TOVS Pathfinder Path A dataset. Bull. Amer. Meteorol. Soc., 78, 1449-1472, doi: 10.1175/1520-0477(1997)078<1449:COTTPP >2 .0.CO;2. [Link]

Tangang, F. T., 2001: Low frequency and quasi-biennial oscillations in the Malaysian precipitation anomaly. Int. J. Climatol., 21, 1199-1210, doi: 10.1002/joc.676. [Link]

Trenberth, K. E., 1998: Atmospheric moisture residence times and cycling: Implications for rainfall rates and climate change. Clim. Change, 39, 667-694, doi: 10.1023/A:1005319109110. [Link]

Trenberth, K. E., J. Fasullo, and L. Smith, 2005: Trends and variability in column-integrated atmospheric water vapor. Climate Dyn., 24, 741-758, doi: 10.1007/s00382005-0017-4. [Link]

Varikoden, H., B. Preethi, A. A. Samah, and C. A. Babu, 2011: Seasonal variation of rainfall characteristics in different intensity classes over Peninsular Malaysia. J. Hydrol., 404, 99-108, doi: 10.1016/j.jhydrol.2011.04.021. [Link]

VonderHaar, T. H., R. J. Engelen, J. M. Forsythe, D. L. Randel, B. C. Ruston, S. Woo, and J. Dodge, 2001: Continuation of the NVAP global water vapor data sets for Pathfinder science analysis. Annual Report, Aug. 2000 - Aug. 2001, STCTR-3269(4), No. 20010107843 , Science and Technology Corp., Hampton, VA, United States.

Wang, H., A. J. Pitman, M. Zhao, and R. Leemans, 2003: The impact of land-cover modification on the June 
meteorology of China since 1700, simulated using a regional climate model. Int. J. Climatol., 23, 511-527, doi: $10.1002 /$ joc.889. [Link]

Wang, J., H. L. Cole, D. J. Carlson, E. R. Miller, K. Beierle, A. Paukkunen, and T. K. Laine, 2002: Corrections of humidity measurement errors from the Vaisala RS80 radiosonde-Application to TOGA COARE data. $J$. Atmos. Ocean. Technol., 19, 981-1002, doi: 10.1175/1 520-0426(2002)019<0981:cohmef>2.0.co;2 . [Link] Willoughby, A. A., T. O. Aro, and I. E. Owolabi, 2002: Seasonal variations of radio refractivity gradients in Nigeria. J. Atmos. Sol.-Terr. Phys., 64, 417-425, doi: 10.1016/s1364-6826(01)00111-0. [Link]

Wong, C. L., R. Venneker, S. Uhlenbrook, A. B. M. Jamil, and Y. Zhou, 2009: Variability of rainfall in Peninsular Malaysia. Hydrol. Earth Syst. Sci. Discuss., 6, 54715503, doi: 10.5194/hessd-6-5471-2009. [Link] 